\title{
Determinants of the Median Nerve Cross Sectional Area in Rheumatoid Arthritis Patients
}

\author{
Suad Hannawi, Haifa Hannawi, Issa Al Salmi
}

\begin{abstract}
BACKGROUND: Rheumatoid arthritis (RA) is a widely recognized cause of carpal tunnel syndrome (CTS). Others stated that CTS is overestimated in RA. CTS is associated with increase in the thickness of the median nerve. This study aims to establish the determinants of the median nerve cross sectional area (MNCSA) in RA patients with no CTS.
\end{abstract}

METHODS: Ultrasound measurements were performed in 120 RA patients $(240$ hands)without symptoms or diagnosis/previous diagnosis of CTS. Eachmedian nerve was measured three times, and the mean value was used for analyses.

RESULTS: MNCSA was $9.79 \pm 2.6 \mathrm{~mm}^{2}$ (range $1.5-22.25$ ) MNCSA was positively associated with the age of participants (p=0.03, CI:0.00-0.08), body mass index (BMI) (p=0.04, CI:0.00-0.21), uric acid level ( $p=0.033$, CI:0.00-0.01), and urine microalbumin $(p=0.04, \quad C I: 0.00-0.01) . \quad R A$ clinical characteristics and inflammatory markers showed no significant relation to the MNCSA.

CONCLUSION:MNCSA in RA is affected by age, BMI, serum uric acid and microalbumin level.

Index Terms - Median Nerve, Renal Function, Rheumatoid Arthritis, ,Inflammation, Ultrasound, Uric Acid, ,.

\section{INTRODUCTION}

Rheumatoid arthritis (RA) is a chronic inflammatory disease that affects joints and synovium. Extra-articular manifestation of RA such as subcutaneous nodules, pulmonary fibrosis, and peripheral neuropathy is seen in up to $10-20 \%$ of patients. Subclinical carpal tunnel syndrome (CTS) had been described in RA with a pooled prevalence of $14 \%[1]$.

Entrapment neuropathy result in a distal sensory, or in a combined sensory and sensorimotor neuropathy [2]-[4].CTS is the most common form of entrapment neuropathies, which occur because of acute or chronic compressive injury of the median nerve at the wrist. Tenosynovial proliferation of the flexor tendons, joint erosions and ligamentous laxity result in loss of carpal tunnel height and increases pressure in the carpal tunnel [1]-[4], results in compression of the median nerve and vessels in the perineurium causing median nerve ischemia and CTS in RA [4]. Other mechanisms found to contribute to CTS development in RA are drug toxicity, vasculitis and amyloidosis [5].lately numerous studies demonstrated that ultrasound is valuable diagnosing tool for CTS diagnosis [6].

In this study, we aimed to investigate the median nerve

SuadHannawi, Associate Professor, Ministry of Health and Prevention, Dubai, United Arab Emirates

Haifa Hannawi, Associate Professor, Ministry of Health and Prevention, Dubai, United Arab Emirates

Al Salmi, Professor, Royal Hospital, Muscat, Oman cross sectional area (MNCSA) in patients with RAwho have no symptoms or signs of CTS, and never been diagnosed to have CTS. We looked at the effect of the RA clinical characteristics, inflammatory markers and renal parameters on the MNCSA.

\section{SUBJECTS AND METHODS}

\section{A. STUDY PARTICIPANTS}

Patients with RA (120 patients) recruited from May 2012 till December 2016,through a specialized rheumatology clinic.

All the patients gave written consent according to the Declaration of Helsinki, and the study was approved by the Central Research Ethics Committee of our health institute.

\section{B. CLINICAL ASSESMENT}

RA was defined according to the revised criteria of the American College of Rheumatology [7]. All the Clinical evaluation was carried out by one rheumatologist ( $\mathrm{SH})$.

Patients with thyroid, diabetes mellitus, renal, liver disease, pregnant women, gout and history of peripheral neuropathy, current symptoms of CTS and history of previous carpal tunnel release were excluded from the study.

Age, gender, alcohol and smoking consumption(current/past smoking, duration of smoking and number of cigarettes per day) were assessed with standardized patient assessment form. Also, patients were questioned about symptoms suggestive of the CTS or any neuropathy in other distribution.

Past medical history was obtained by reviewing doctors' electronic charts including RA duration, age at RA symptoms onset, presence of rheumatoid factor (RF), rheumatoid level (NR: 0.0- morbidities (i.e. Diabetes, thyroid diseases, renal and liver diseases, previous carpal tunnel release and gout). Gout was defined as either use of hypouricemic agents or clinical diagnosis.

The patients underwent detailed physical examination and laboratory investigations before ultrasound (US) measurement. Systolic blood pressure (SBP) and diastolic blood pressure (DBP)) measured in the right upper arm of patients in a seated position using an automatic oscillometric blood pressure recorder. Patients were examined for joints tenderness and swelling.Neurological examination was performed with standard assessment including muscle strength, sensory testing (light touch, pinprick, position, temperature, and vibration sense). Patients were examined for the presence of Tinel's sign, Phalen test, thenaratrophy and Flick sign.Standing height and weight were measured.

A fasting blood sample was obtained for measurement of 
serum uric acid (SUA) (NR: 155-476 $\mu$ mole/L), plasma glucose (NR: 4.6-6.4 mmole/L), total cholesterol (NR: 2.0-2.5 mmole/L), erythrocyte sedimentation rate (ESR; NR: 0.0-30 $\mathrm{mm} / \mathrm{hr}$.) and C-reactive protein rate (CRP; 0.0-5.0 $\mathrm{mg} / \mathrm{L}$ ), high density lipoprotein (HDL; NR: 1.0-1.6 mmole/L), low density lipoprotein (LDL; NR: 0.0-2.5 mmole/L), triglycerides (TG; NR: 0.4-1.9 mmole/L), urea (NR: $0.0-8.3$ mmole/L) and creatinine (NR: 44-133 $\mu$ mole/L). Microalbuminuria was defined from elevated concentrations of albumin in a spot sample (20 to <200 mg/L) [8].

Score for the Disease Activity Score-28 joints (DAS-28) was calculated usingESR.BMI was calculated using the formula of weight in kilograms divided by height in meters. Glomerular Filtration Rate (GFR) calculated using Modification of Diet in Renal Disease (MDRD) formula.

\section{MNCSA ULTRASOUND (US) MEASURMENTS}

All the MNCSA US measurements were performed bilaterally on all patients by one qualified sonographer. Patients were lying on the bed on a supine position, with their forearm in a supinated resting position on a small table. The US probe (an 8-16 MHz linear array transducer) was held as lightly as possible to not disturb the anatomy of the nerve. The median nerve was examined at the entrance of the carpal tunnel, between the pisiform bone and tubercle of the navicular, for which the distal volar crease is an external landmark. The cross-sectional area of the median nerve was calculated directly by the software of the US equipment. Each median nerve was examined three times, and the mean value was used in further calculations.

During the inclusion of RA participants for this study, $9 \%$ were excluded because of division of their median nerve at the entrance of the carpal tunnel; that is 12 out of 132 patients, left with 120 patients.

\section{STATISTICAL ANALYSIS}

Summary statistical analysis results were expressed as percentages for categorical data and mean \pm standard deviation (SD) for continuous variables. The correlation between MNCSA and other variables were calculated using simple linear regression analysis with MNCSA as a dependent variable. Covariates were renal function parameters, traditional cardiovascular risk factors, and inflammatory markers. $P$ value of less than 0.05 were accepted as statistically significant. Multivariate model included all the variables that were significantly related to the MNCSA in the univariate models. All statistics were performed using STATA program.

\section{RESULTS}

All the participants were free of thyroid, diabetes mellitus, renal, liver disease, pregnancy, gout, history of peripheral neuropathy, current symptoms of CTS and history of previous carpal tunnel release.

\section{A. STUDY PARTICIPANTS, RA CLINICAL CHARACTERITICS AND INFLAMMATORY MARKERS}

The study included 240 hands of 120 rheumatoid arthritis patients (104 females (87\%), and 16 (13\%)males. Average age was49 \pm 13 years. $92(77 \%)$ patients were rheumatoid factor seropositive. The mean duration of rheumatoid arthritis was $77 \pm 107$ months. The mean ESR was $33 \pm 24$ $\mathrm{mm} / \mathrm{hr}$, mean CRP was $9.4 \pm 17 \mathrm{mg} / \mathrm{dl}$. The average GFR was $124 \pm 34 \mathrm{ml} / \mathrm{min}$ (62-286).The demographic and the clinical characteristics of RApatients are displayed in table 1.

\section{B. MEDIAN NERVE THICKNESS}

Then mean MNCSA among our study participants was $9.79 \pm 2.6 . \mathrm{mm}^{2}$ (range $1.5-22.25$ ).

The MNCSA was positively associated with the age of participants ( $p=0.03, \mathrm{CI}: 0.00,0.08)$, BMI ( $\mathrm{p}=0.04$, CI: 0.00 , $0.21)$, SUA ( $\mathrm{p}=0.033$, CI:0.00, 0.01$)$, and urine microalbumin $(\mathrm{p}=0.04, \mathrm{CI}: 0.00,0.01)$. GFR level, inflammatory markers (ESR and CRP) and other RA disease activity markers showed no significant relation to the MNCSA.

Multiple regression analysis that included age, sex, renal parameters and inflammatory markers, showed a persistence significant positive relationship of the age of the participants to the MNCSA ( $p=0.03$, CI: $0.003,0.011$ ).

\section{DISCUSSION}

Rheumatoid arthritis is associated with autonomic and entrapment neuropathy resulting in distal sensory or combined sensory-motor neuropathy [9],[10].

Carpal tunnel syndrome is the most common upper limb entrapment neuropathy in the general population and in RA [11],[12] caused by compression of the median nerve in the carpal tunnel beneath the flexor retinaculum. The existence of subclinical neuropathy can be achieved by electro-diagnostic studies and by ultrasound[13].

As no previous study looked at the determinants of the cross-sectional area of the median nerve in patients with arthritis with no carpal tunnel syndrome. This study,provided data about MNCSA in RA patients and itsrelation to the inflammatory markers and renal function in rheumatoid arthritis patients, provide a new paradigm for further future studies in this field.

\section{A. MEDIAN NERVE AND ULTRA-SONOGRAPHIC ASSESSMENT}

US has been found to be a precise method to display the anatomy of the median nerve [11]., and several studies have shown that US have high sensitivity and specificity for the diagnosis of idiopathic CTS [14]-[17].More, evaluation of the median nerve by assessing cross sectional area at the wrist inlet had been found as a sensitive and specific test in RA and in general population [18].

\section{B. MNCSA AND CTS SYMPTOMS}

In general practice $10 \mathrm{~mm}^{2} \mathrm{MNCSA}$ is used as a cutoff value[19],[20].Increased MNCSA is highly correlated with CTS clinical symptoms [21],[22]. CSA of 10-13 $\mathrm{mm}^{2}$ have been reported in patients with mild symptoms [6]., and could raise the suspicion of CTS in patients with RA [23]. RA patients without symptoms or signs of CTS have same MNCSA as healthy controls[13]. This is in consistence with the MNCSA in our patients who had no symptoms or clinical sings of CTS. However, unlike our study, they did not look at the determinants of MNCSA in RA population. 


\section{MNCSAAND THE RA CLINICAL}

\section{CHARACTERISTICS AND INFLAMMTORY ACTIVITIES}

Previous studies showed that in healthy individual, the MNCSA at the level of entrance into the carpal tunnel has the highest diagnostic sensitivity and specificity for CTS. Normal range of the MNCSA is between $7.0 \pm 1.0 \mathrm{~mm}^{2}$ and $10.2 \pm 2.5 \mathrm{~mm}^{2}[15]-[17]$. The range of the MNCSA in our study participants was found to be within the reported normal range. This is of no surprise considering that mean MNCSA in RA patients without signs and symptoms of CTS found to be like healthy control in a previous study with no significant relationship between the median nerve involvement and clinical or laboratory parameters in RA [1]. This is consistentwith our findings that no RA clinical characteristicsor inflammatoryactivities markers has a relation to the MNCSA. However, othersfound a significant association between RA disease duration and the occurrence of CTS [23],[24].Karadag et al disclosed that age, disease duration and functional scores were higher among the RA patients with CTS [23]. The mean duration of RA in our study is 77 months and may be this time is not sufficient for RA patients to develop CTS. Additional explanation for the normal range of the MNCSA in our study might be attributed to the young average age of the participants.

\section{MEDIAN NERVE CSA AND THE AGE OF THE PARTICIPANTS}

Age influence the MNCSA and the development of theCTS[25],[26], with a higher prevalence of delayed median nerve in those who are above 50 years of age [27]. In RA, age had been found to be significantly higher in those who have CTS [23] and in those who have peripheral neuropathy [28]. Therefore, our results of positive association between the age of RA patients and the MNCSA is in line with what have been reported earlier.

\section{E. MNCSA ANDBMI}

The data of the relationship between the MNCSA and the body weight is not consistence. Although some studies showed that obesity does not influence carpal canal pressure or the size of the median nerve at the wrist. Others reported a strong association between slowed median nerve conduction and increased nerve size in individuals with BMI of more than 29. BMI> 29 is associated with 2.5 times more risk of CTS compares to individual with $\mathrm{BMI}<20$ [29].

Our results of a positive linear relationship between MNCSA and the BMIis agreeing with the findings of Werner et al [29]., and contradictory to Hammer et al, who found a relationship between the cross-sectional areas of the median nerves and height and weight in healthy controls, but not in RA patients[13]. However,Hammer et alprovided no reasons for the discrepancy.Hammer et al suggested that their finding implies that neither height nor weight should be considered to have a major impact on the evaluation of the measured area of the median nerve in an RA patient[13]. From public health prospective, this unlikely to be right.

\section{F. MEDIAN NERVE CSA AND MICROALBUMINURIA}

Microalbuminuria is defined as urinary excretion of albumin that is persistently increased above normal but below the sensitivity of conventional semi quantitative test strips. Microalbuminuria is a sign of glomerular dysfunction in general and to a lesser extent a sign of tublointerstitial disease[30].

Among diabetic patient, median nerve motor conduction velocity was significantly slower, and CTS is higher in microalbuminuric $(48.4(1.4) \mathrm{m} / \mathrm{s})$ than in normoalbuminuric (52.7(1.2) $\mathrm{m} / \mathrm{s}, \mathrm{p}=0.04)[31]$. In the view of absence of previous studies to examine the MNCSA and mircroalbuminruia in RA setting, our study is the first to report a significant association between MNCSA and microalbuminuria, in a similar fashion to what had been reported in the diabetic population.

\section{LIMITATION AND STRENGTH}

This study is limited by our failure to control for participants occupations which may contribute to the development of CTS.

The strength of our study is in the fact that we excluded patients with diseases that might affect the MNCSA (such as diabetes, thyroid dysfunction, renal and liver diseases, gout and pregnancy). The study also excluded patients with CTS symptoms/clinical sings and those who had a previous history of carpal tunnel release. Also, the US assessment carried out in our study was the cross-sectional area at the entrance of the carpal tunnel which had been reported to have the highest sensitivity and specificity for CTS [[14]-[17].

\section{CONCLUSION}

Among RA population, MNCSA is affected by age, BMI, serum uric acid and microalbumin level. Monitoring of the subclinical renal dysfunction and body weight control might be of help to reduce CTS occurrence.

$\begin{array}{lc}\text { ABBREVIATIONS } & \text { Body mass index } \\ \text { BMI } & \text { C-Reactive Protein } \\ \text { CRP } & \text { Carpal Tunnel Syndrome } \\ \text { CTS } & \text { Disease Activity Score } \\ \text { DAS } & \text { Erythrocyte Sedimentation } \\ \text { ESR } & \text { Rate } \\ & \text { Glomerular filtration rate } \\ \text { GFR } & \text { High density lipoprotein } \\ \text { HDL } & \text { Low density lipoprotein } \\ \text { LDL } & \text { Median Nerve Cross } \\ \text { MNCSA } & \text { Sectional Area } \\ & \text { Rheumatoid Arthritis } \\ \text { RA } & \text { Serum Uric Acid } \\ \text { SUA } & \text { Triglyceride } \\ \text { TG } & \text { Ultrasound }\end{array}$

\section{CONSENT}

Study carried out in compliance with the Helsinki Declaration. Approval was obtained from the Ethical committee of the Ministry of Health and Prevention of UAE. Written informed consent was obtained from the participants.

\section{COMPETING INTEREST}

The authors declare that they have no competing interests.

\section{AUTHORS' CONTRIBUTION}

HS wrote the manuscript. $\mathrm{AI}$ and $\mathrm{HH}$ edited the 
manuscript. All authors read and approved the final manuscript.

\section{ACKNOWLEDGEMENTS}

We thank all the study participants for their participation and for helping us to conduct this study.

\section{TABLE 1. DEMOGRAPHIC DETAILS, RA CHARACTERISTICS, AND LABORATORY VALUES OF RA}

\section{PATIENTS}

\section{Demographic Details}

Male:Female

$16: 104$

Mean age (SD, yr)

$49(13)$

\section{Rheumatoid arthritis characteristics}

Disease duration, mean (SD, months)

Tender joint count (of 28)

Swollen joint count (of 28)

Morning stiffness duration (minutes)

Disease activity score (DAS) 3v-ESR

$92(78 \%)$

Laboratory values

Albumin level ()

Total protein

69 (18)

$33(24)$

$9.4(17)$

$4.6(1.0)$

$1.2(0.7)$

$1.4(0.4)$

$2.7(0.9)$

HDL level (mmol/L)

LDL cholesterol (mmol/L)

Renal parameters

GFR

Uric acid level

Urinary microalbumin

Urinary protein

111(103)

\section{Cardiovascular risk factors}

Body mass index $\left(\mathrm{kg} / \mathrm{m}^{2}\right) *$

Smoking, ever, n (\%)

Systolic blood pressure 75 (10)

RA: Rheumatoid Arthritis, ESR: Erythrocyte Sedimentation Rate, CRP: C-reactive protein, LDL: low Density Lipoprotein, HDL: High Density Lipoprotein, GFR: Glomerular Filtration Rate, n: number, SD: standard Deviation 
TABLE. 2 UNIVARIATE AND MULTIVARIATE LINEAR REGRESSION ANALYSIS OF THE RELATIONSHIP BETWEEN THE MEDIAN NERVE CROSS SECTIONAL AREA, SELECTED RA FEATURES, AND RENAL

$\begin{array}{cccccc}\text { Variables } & \begin{array}{c}\text { Standardized } \\ \boldsymbol{\beta} \text { coefficient }\end{array} & \mathbf{S E} & \mathbf{t} & \mathbf{p} & \mathbf{C I} \\ \text { Univariate model } & & & & & \\ \text { Age* } & 0.041 & 0.019 & 2.20 & \mathbf{0 . 0 3 0} & 0.004,0.077 \\ \text { Age at RA onset } & 0.035 & 0.024 & 1.43 & 0.165 & -0.015,0.086 \\ \text { Male gender* } & & & & 0.240 & \\ \text { History of smoking, ever } & & & & 0.268 & \\ \text { Number of consumed cigarette/day } & 0.147 & 0.185 & 0.80 & 0.427 & -0.220,0.515 \\ \text { Duration of smoking } & 0.138 & 0.074 & 1.84 & 0.076 & -0.015,0.291 \\ \text { Systolic blood pressure } & 0.005 & 0.010 & 0.58 & 0.563 & -0.014,0.026 \\ \text { Diastolic blood pressure } & 0.002 & 0.025 & 0.11 & 0.914 & -0.047,0.053 \\ \text { Body mass index } & 0.109 & 0.053 & 2.05 & \mathbf{0 . 0 4 3} & 0.003,0.214 \\ \text { Morning stiffness (minutes) } & 0.001 & 0.001 & 1.15 & 0.261 & -0.001,0.004 \\ \text { Number of swollen joints (28) } & 0.066 & 0.068 & 0.96 & 0.346 & -0.074,0.207 \\ \text { Number of tender joints (28) } & 0.013 & 0.032 & 0.40 & 0.692 & -0.053,0.080 \\ \text { ESR* } & 0.007 & 0.010 & 0.71 & 0.479 & -0.013,0.028 \\ \text { C-Reactive Protein * } & -0.012 & 0.015 & -0.82 & 0.413 & -0.413, .018 \\ \text { DAS-28 (ESR) } & & & & & \\ \text { RA nodules presence } & & & & 0.243 & \\ \text { RF presence * } & & & & 0.210 & \\ \text { RF level } & -0.047 & 0.156 & -0.30 & 0.762 & -0.357,0.262 \\ \text { LDL } & 0.254 & 0.300 & 0.85 & 0.400 & -0.400,0.853 \\ \text { HDL } & 0.083 & 0.690 & 0.12 & 0.905 & -1.291,1.457 \\ \text { Cholesterol } & 0.213 & 0.259 & 0.82 & 0.413 & -0.302,0.729 \\ \text { TG } & -0.353 & 0.368 & 0.96 & 0.341 & -0.379,1.086 \\ \text { Total protein } & -0.001 & 0.013 & -0.10 & 0.924 & -0.028,0.026 \\ \text { Albumin } & 0.055 & 0.060 & 0.92 & 0.362 & -0-.064,0.175 \\ \text { SUA * } & 0.006 & 0.003 & 2.17 & \mathbf{0 . 0 3 3} & 0.000,0.011 \\ \text { Urine microalbumin level* } & 0.007 & 0.003 & 2.05 & \mathbf{0 . 0 4 4} & 0.000,0.014 \\ \text { Glomerular filtration rate } & 0.002 & & & & \\ \text { Multivariate model } & & & & & \\ \text { Age } & 0.063 & 0.029 & 2.15 & \mathbf{0 . 0 3 0} & 0.003,0.011\end{array}$

\section{FUNCTION PARAMETERS IN 120 PATIENTS (240 HANDS) WITH ESTABLISHED RA}

DAS-28 (ESR): Disease Activity Score-28 (Erythrocyte Sedimentation rate), ESR: Erythrocyte Sedimentation Rate, RA:

Rheumatoid Arthritis, RF: Rheumatoid Factor, LDL: low Density Lipoprotein, HDL: High Density Lipoprotein, SUA: Serum Uric Acid, TG: Triglyceride.

Each parameter included in the multiple linear regression analysis * is presented.

\section{REFERENCES}

[1] Sakthiswary R, Singh R (2017) Has the median nerve involvement in rheumatoid arthritis been overemphasized? Rev Bras Reumatol Engl Ed 57: 122-128

[2] Sivri A, Guler-Uysal F (1999) The electroneurophysiological findings in rheumatoid arthritis patients. Electromyogr Clin Neurophysiol 39: 387-391.

[3] Toussirot E, Serratrice G, Valentin P (1993) Autonomic nervous system involvement in rheumatoid arthritis. 50 cases. J Rheumatol 20: $1508-1514$

[4] Shinoda J, Hashizume H, McCown C, Senda M, Nishida K, et al. (2002) Carpal tunnel syndrome grading system in rheumatoid arthritis. J Orthop Sci 7: 188-193.

[5] Golding DN (1971) Rheumatoid neuropathy. Br Med J 2: 169.

[6] Yagci I, Akdeniz Leblebicier M, Mansiz Kaplan B, Ozturk Gokbakan D, Akyuz G (2016) Sonographic Measurements Can Be Misleading for Diagnosing Carpal Tunnel Syndrome in Patients with Rheumatoid Arthritis. Acta Reumatol Port 41: 40-44.

[7] Arnett FC, Edworthy SM, Bloch DA, McShane DJ, Fries JF, et al. (1988) The American Rheumatism Association 1987 revised criteria for the classification of rheumatoid arthritis. Arthritis Rheum 31: 315-324.
[8] de Jong PE, Curhan GC (2006) Screening, monitoring, and treatment of albuminuria: Public health perspectives. J Am Soc Nephrol 17: 2120-2126.

[9] Wein TH, Albers JW (2002) Electrodiagnostic approach to the patient with suspected peripheral polyneuropathy. Neurol Clin 20: 503-526, vii.

[10] Beltran J, Rosenberg ZS (1994) Diagnosis of compressive and entrapment neuropathies of the upper extremity: value of MR imaging. AJR Am J Roentgenol 163: 525-531.

[11] Kamolz LP, Schrogendorfer KF, Rab M, Girsch W, Gruber H, et al. (2001) The precision of ultrasound imaging and its relevance for carpal tunnel syndrome. Surg Radiol Anat 23: 117-121.

[12] Filippucci E, Unlu Z, Farina A, Grassi W (2003) Sonographic training in rheumatology: a self teaching approach. Ann Rheum Dis 62 565-567.

[13] Hammer HB, Hovden IA, Haavardsholm EA, Kvien TK (2006) Ultrasonography shows increased cross-sectional area of the median nerve in patients with arthritis and carpal tunnel syndrome. Rheumatology (Oxford) 45: 584-588.

[14] Swen WA, Jacobs JW, Bussemaker FE, de Waard JW, Bijlsma JW (2001) Carpal tunnel sonography by the rheumatologist versus nerve conduction study by the neurologist. J Rheumatol 28: 62-69.

[15] Wong SM, Griffith JF, Hui AC, Lo SK, Fu M, et al. (2004) Carpal tunnel syndrome: diagnostic usefulness of sonography. Radiology 232: 93-99. 
[16] Duncan I, Sullivan P, Lomas F (1999) Sonography in the diagnosis of carpal tunnel syndrome. AJR Am J Roentgenol 173: 681-684.

[17] Wong SM, Griffith JF, Hui AC, Tang A, Wong KS (2002) Discriminatory sonographic criteria for the diagnosis of carpal tunnel syndrome. Arthritis Rheum 46: 1914-1921.

[18] Ryan MM, Samuels J (2009) Musculoskeletal Ultrasound Assessment Of Carpal Tunnel Syndrome In Rheumatoid Arthritis. Arthritis \& Rheumatism 60: 1460 .

[19] Roll SC, Evans KD, Li X, Freimer M, Sommerich CM (2011) Screening for carpal tunnel syndrome using sonography. J Ultrasound Med 30: 1657-1667.

[20] Wiesler ER, Chloros GD, Cartwright MS, Smith BP, Rushing J, et al (2006) The use of diagnostic ultrasound in carpal tunnel syndrome. J Hand Surg Am 31: 726-732.

[21] Kotevoglu N, Gulbahce-Saglam S (2005) Ultrasound imaging in the diagnosis of carpal tunnel syndrome and its relevance to clinical evaluation. Joint Bone Spine 72: 142-145.

[22] Buchberger W, Judmaier W, Birbamer G, Lener M, Schmidauer C (1992) Carpal tunnel syndrome: diagnosis with high-resolution sonography. AJR Am J Roentgenol 159: 793-798.

\section{Authors profile}

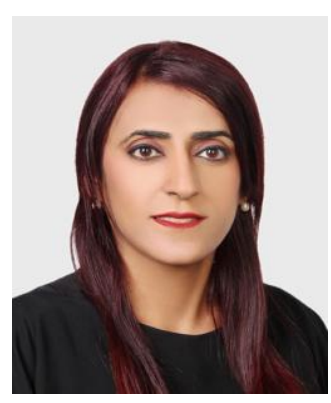

Corresponding author: SuadHannawi, Associate Professor, Ministry of Health and Prevention, Dubai, United Arab Emirates .SuadHannawi, BhSc; MD; MRCP (UK), FRCP (UK); MIPH (AUS), PHD (AUS), a consultant of Rheumatology at the Ministry of Health and Prevention (MOHAP) of UAE. After receiving her Bachelor of Science (BhSc), and the Medical Diploma (MD) degree, Dr. Hannawi obtained the fellowship of Royal College of Physicians of Edinburgh and completed her clinical training of Rheumatology in Australia. Dr. Hannawi proceeded with her academic attainment by obtaining a $\mathrm{PhD}$ in Rheumatology with the thesis of "Early Rheumatoid Arthritis, Inflammation and Atherosclerotic disease".

Her Interest in the Public Health motivated her to proceed with getting a Master on International Public Health from University of Queensland, Australia, with Dean's Commendation for High Achievement.

Dr. Hannawi has published in number of journals and has presented at different national and international conferences. Dr. Hannawi is a reviewer for many Rheumatology journals including Journal of Rheumatology, Seminar in Arthritis and Rheumatism, Arthritis Research and Therapy, Journal of clinical Rheumatology, Arthritis Care and Research, and many others. and currently Dr. Hannawi has more than 40 publications.

Currently Dr. Hannawi is the Deputy Chair of the Central Research Committee of the MOHAP, Chairman of Dubai District Research Committee, and a representative of the United Arab Emirates in the Gulf Cooperation Countries (GCC) Medical Research Committee.

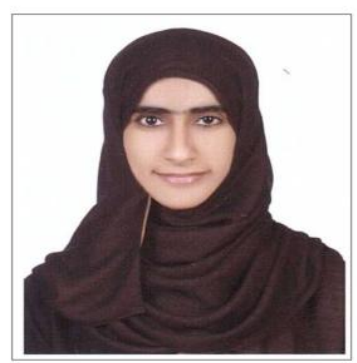

Co-author: Haifa Hannawi, Associate Professor, Ministry of Health and Prevention, Dubai, United Arab Emirates, P.O. Box 65522, Tel: +9715045454939, Email: haifa.hannawi@moh.gov.aeHaifa Hannawi, BDS, MDSc, FRACDS (Australia), PhD (Australia). Dr. Hannawi is a senior lecturer and Asst. Professor at Mohammed Bin Rashid Medical College and she is the head of the Periodontal Diseases Master Program. Dr. Hannawi is a member of the Central Research Committee of the Ministry of Health and Prevention of UAE, and the Deputy chairman of Dubai research committee of MOHAP. Dr. Hannawi published in number of journals

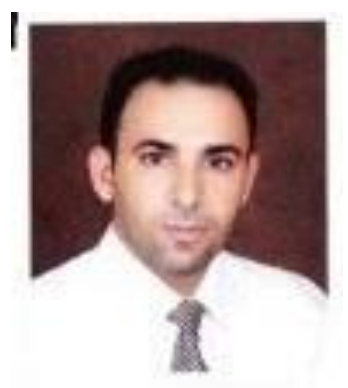

Co-author: Issa Al Salmi, Professor, Royal Hospital, Muscat, Oman

Issa Al Salmi MD, BA, MB, Bch, BAO, FRCPI MRCP (UK), FRCP, MIPH (AUS), $\mathrm{PhD}$ (AUS), FASN (USA) , Senior Consultant Physician at the Medical Department, The Royal Hospital, Muscat, Oman. Dr. Al Salmi is the President of Kidney Services in Oman, President of the Nephrology Fellowship Board, OMSB, Head of the Research Committee at the Royal Hospital and in the Omani medical specialty board research department. Dr. Al Salmi is a Board Member of the International Society of Nephrology and of the Research Council Committee. Dr. Al Salmi is a Senior Clinical Lecturer at Sultan Qaboos University (SQU), host Examiner of Arab Board of Internal Medicine, Host Examiner for the Royal College of Physicians of UK and Ireland. Dr. Al Salmi is reviewer for many journals and published extensively in many international journals. 